\title{
Evaluation of Adherence to Nevirapine for Prevention of Mother-to-Child Transmission amongst Infants of HIV Positive Mothers in the First 6 Weeks of Life in Lagos Nigeria
}

\author{
Obiyo Nwaiwu ${ }^{1}$, Folasade A. Olatunde ${ }^{1}$, Nkechinyere E. Harrison ${ }^{2}$, Margaret O. Ilomuanya ${ }^{3}$, \\ Oludaisi A. Oduniyi ${ }^{1}$ \\ ${ }^{1}$ Department of Pharmacology, Therapeutics and Toxicology, College of Medicine, University of Lagos, Surulere, Lagos, Nigeria \\ ${ }^{2}$ Department of Medicine, 68 Nigerian Army Reference Hospital (68 NARH), Yaba, Lagos, Nigeria \\ ${ }^{3}$ Department of Pharmaceutics and Pharmaceutical Technology, Faculty of Pharmacy, University of Lagos, Surulere, Lagos, Nigeria \\ Email: *obinwa21566@yahoo.com, *onwaiwu@unilag.edu.ng
}

How to cite this paper: Nwaiwu, O., Olatunde, F.A., Harrison, N.E., Ilomuanya, M.O. and Oduniyi, O.A. (2019) Evaluation of Adherence to Nevirapine for Prevention of Mother-to-Child Transmission amongst Infants of HIV Positive Mothers in the First 6 Weeks of Life in Lagos Nigeria. World Journal of AIDS, 9, 70-84.

https://doi.org/10.4236/wja.2019.92006

Received: April 5, 2019

Accepted: June 1, 2019

Published: June 4, 2019

Copyright $\odot 2019$ by author(s) and Scientific Research Publishing Inc. This work is licensed under the Creative Commons Attribution International License (CC BY 4.0).

http://creativecommons.org/licenses/by/4.0/

\section{Abstract}

Background: Over $90 \%$ of infection in children is acquired through mother to child transmission (MTCT). Nevirapine's efficacy, safety and affordable cost make it the most preferred non-nucleoside reverse transcriptase inhibitor (NNRTI) for paediatric prophylactic use in resource limited settings. There are very few studies on pediatric adherence to antiretroviral prophylaxis, especially in very young infants. The objective of the study was to evaluate the adherence to nevirapine for prevention of mother to child transmission (PMTCT) amongst infants of HIV positive mothers in the first 6 weeks of life. Methods: This was a questionnaire based prospective cross-sectional multicenter study initiated in July 2015 and concluded in December 2017. The study was carried out at the Aids Prevention in Nigeria (APIN/HIV) human immunodeficiency paediatric clinics of the Lagos University Teaching Hospital (LUTH), Idi-Araba, Lagos State, 68 Nigerian Army Reference Hospital Yaba (68NARHY) Lagos, Nigeria and the Holy Family Catholic Hospital, Festac Town, Amuwo Odofin, Lagos State. Nevirapine adherence, in infants of 0 - 6 weeks was measured by maternal verbal reports. Results: Eighty-one (81) infants receiving nevirapine within the age of 0 - 6 weeks completed the study. Majority of the infants started treatment at birth (32\%) and after 4 weeks ( $31 \%$ ). $54 \%$ of the 81 respondents do not miss or skip their doses while $46 \%$ of respondents skip doses. Majority of the respondents 18 (49\%) missed their doses for 24 - 48 hours while $25 \%$ missed their doses because they were away from home and $23 \%$ ran out of pills. $85.2 \%$ took $\geq 95 \%$ of the prescribed medications (good or high adherence ), $8.2 \%$ took $80 \%-95 \%$ of doses (mod- 
erate adherence) while $6.2 \%$ took $<80 \%$ of prescribed medicines (low Adherence). The reasons for missed doses were significantly associated with the adherence levels $(p<0.05)$. Gender, age of child and mother, level of education and occupation of the mothers did not significantly affect the level of adherence. $(p>0.05)$. Conclusions: The adherence rates found in this study are comparable to other studies in developing countries. But these rates are still low for good clinical outcomes. Different levels of adherence were documented with the majority having good or high adherence. Not all of the infants started treatment at birth and Institutional delivery should be encouraged to improve early initiation of prophylaxis. The finding of patients with low adherence rates among the study population calls for intensification of counselling on adherence and should continue to be an integral part of prevention of mother to child transmission. Improved access to antiretroviral agents and improved care delivery systems are important.

\section{Keywords}

Adherence, Infants, Antiretroviral Prophylaxis, Maternal/Caregiver Verbal Reports, Nevirapine, Six Weeks

\section{Introduction}

Human immunodeficiency virus (HIV) remains a leading cause of death in Sub-Saharan Africa [1]. The human immunodeficiency virus (HIV) can be transmitted from an HIV-positive woman to her child during pregnancy childbirth and breastfeeding [2] [3]. The prevalence rate of Mother to child transmission (MTCT) in Nigerian states ranges from $1.0 \%$ to $10.6 \%$ [4].

Effective antiretroviral (ARV) regimens inhibit viral replication, which can preserve or restore immune function. Early studies have demonstrated that infant antiretroviral (ARV) prophylaxis in the first 6 weeks of life could significantly reduce risk of intrapartum or early breastfeeding transmission of HIV [5].

Prevention of mother-to-child transmission (PMTCT) guidelines currently recommend that nevirapine suspension must be given to all HIV exposed infants at birth and for 6 weeks thereafter as post-exposure prophylaxis for intrapartum and early breastfeeding transmission, irrespective of feeding practice or maternal ARV treatment options [6] [7]. The revised National PMTCT guidelines recommend daily nevirapine for the first 6 weeks of life starting as soon as possible after birth, preferably within 72 hours of birth [4]. Nevirapine (NVP) belongs to the family of non-nucleoside analogue reverse transcriptase (RT) inhibitors [8]. The efficacy of NVP for the treatment of HIV infection has been proven in multiple clinical trials [9] [10]. However, as single substitutions at several RT positions have been reported to confer resistance to NVP and should be used carefully [11] [12]. Excellent adherence is therefore very important for prevention of emergence of resistance and success of MTCT [13] [14]. 
Adherence to antiretroviral treatment regimens in children and adults are well documented in both low to middle income and high income countries [15] [16] [17] [18]. However studies on pediatric adherence are limited particularly the prophylactic use of ARV drugs regimens in the and there are also gaps in caregiver knowledge, attitudes and perceptions of antiretroviral treatment and prevention of mother-to-child transmission which influence their decision to adhere to ART [13] [19].

The aim of this study was to evaluate adherence to nevirapine by infants of HIV positive mothers receiving daily nevirapine suspension for prevention of mother-to-child transmission in the first 6 weeks of life.

\section{Materials and Method}

\subsection{Study Setting, Study Population \& Design}

This prospective cross-sectional multicenter study was carried out at the APIN/LUTH paediatric clinic at the Lagos University Teaching Hospital (LUTH), Idi-Araba, Mushin Lagos State, Nigerian Army Reference Hospital (NARH), Yaba Lagos State and the Holy Family Catholic Hospital, Festac Town, Amuwo Odofin, Lagos State from July 2015 and concluded December 2017.

Using a convenient sampling method eighty-one out of the proposed one hundred and thirty-nine (The sample size was calculated level of confidence, of 95\% (1.96) a proportion of target population estimated to be 91\% (Otieno-Nyunya et al., 2007) and the degree of accuracy set at 0.05.) mothers/caregivers of male and female infants of aged 0 - 6 weeks receiving nevirapine gave informed consent and were willing to discuss challenges faced during nevirapine therapy. We excluded infants above 6 weeks and caregivers/mothers that declined to give consent or disclose information HIV exposed infants enrolled in the study received nevirapine suspension $(10 \mathrm{mg} / \mathrm{ml})$ for the first 6 weeks of life. Study visits in the first 6 weeks of life after enrolment (day 3 - 7 after birth) were scheduled for 2, 5 and 6 weeks. The dose at enrolment began at $0.6 \mathrm{ml}(6 \mathrm{mg})$ daily until the 2 week visit at which point the dose increased to $1.5 \mathrm{ml}(15 \mathrm{mg})$ given as a daily dose until the 5 week visit. At this visit, the dose was then increased to 1.8 $\mathrm{ml}(18 \mathrm{mg})$ daily until day 42 (birth = day 0$)$

Measurement of adherence was by maternal/caregiver verbal reports. Information regarding infant adherence was obtained from mothers/caregiver using a structured questionnaire. The questionnaire was adapted from the paediatric AIDS clinical trials group adherence questionnaire module 2-revised [20]. The questionnaire was modified and pretested in a similar setting in 5\% of the sample size. The questionnaire is made up of two sections of socio demographic characteristics of caregiver mother and child, and drug therapy respectively. Questions included whether infants missed doses since the previous visit, the number of days missed and the reason for missed doses. Other information obtained included general reasons for non-adherence. If infants received $\geq 95 \%$ of prescribed doses, adherence was classified as good or high adherence [21]. Poor 
adherence occurred if infants received $<95 \%$ of prescribed doses. Poor adherence was further sub classified for this study if $80 \%-95 \%$ of doses were taken (moderate adherence) and $<80 \%$ (low Adherence). The association between demographic characteristics and missed doses reported by mothers was determined for the longest period (2 - 5 week visit).

\subsection{Statistical Analysis}

Data were analyzed using the statistical package for social sciences SPSS version 16.0. Continuous parametric data were expressed in mean, standard deviation and non-parametric data were expressed in percentages. Results were displayed in tables, figures and charts. Chi-square test was used to test the association between variables. p-value less than 0.05 was regarded as significant.

\subsection{Ethical Approval}

To conduct this study, approval was obtained from the Health Research and Ethics committee of the Lagos University Teaching Hospital, Idi-Araba, Lagos (ADM/DCST/HREC/APP/412) prior to the commencement of the research.

\section{Results}

\section{Socio Demographic Data of the Respondents}

Eighty-one (81) infants receiving nevirapine within the age of 0-6 weeks completed the study. The socio-demographic data of respondents are shown in $\mathrm{Ta}$ ble 1 . The table shows $58 \%$ of the infants were female and $42 \%$ were male. The age group of the infants was as follows: 0 - 2 weeks 3.7\%, 2 - 4 weeks $12.2 \%, 4$ - 6 weeks $84 \%$. Mother's age was distributed as $<20$ years $7.4 \%, 20-30$ years $30.9 \%$, 30 - 40 years $56.8 \%$ and 40 - 50 years $4.9 \%$. Seven percent had primary school education, $46.9 \%$ had secondary school education, $43.2 \%$ had tertiary school education, and $1.2 \%$ had no formal education while $1.2 \%$ gave no response. The classifications of occupation of the mothers are as follows: Students $7.4 \%$, artisans $12.3 \%$, domestic staff $6.2 \%$, service providers $39.5 \%$, professionals $12.3 \%$, house wives $14.8 \%$ and no response $7.4 \%$.

Table 2 shows the frequency and percentage of the onset of nevirapine among infants of HIV positive mothers while Figure 1 below shows the distribution of respondents who miss doses of nevirapine and those who do not. Majority of the infants started treatment at birth (32\%) and after 4 weeks (31\%). Fifty-four percent of the 81 respondents do not miss or skip their doses while $46 \%$ of respondents skip doses.

Table 3 shows the duration of missed doses in the 37 (46\%) patients who missed doses while Table 4 describes the reasons for missed doses of nevirapine by respondents. Majority of the respondents 18 (49\%) missed their doses for 24 48 hours while $25 \%$ missed their doses because they were away from home and $23 \%$ ran out of pills. The respondents gave multiple responses.

Table 5 shows the distribution of respondents who repeat or do not repeat 
Table 1. Demographic characteristics of patients.

\begin{tabular}{|c|c|c|}
\hline Socioeconomic Data & Frequency & Percentage \% \\
\hline \multicolumn{3}{|l|}{ Gender } \\
\hline Male & 34 & $42 \%$ \\
\hline Female & 47 & $58 \%$ \\
\hline Total & 81 & $100 \%$ \\
\hline \multicolumn{3}{|l|}{ Age of Child } \\
\hline 0 to 2 Weeks & 3 & $4 \%$ \\
\hline 2 to 4 Weeks & 10 & $12 \%$ \\
\hline$>4$ Weeks to 6 Weeks & 68 & $84 \%$ \\
\hline Total & 81 & $100 \%$ \\
\hline \multicolumn{3}{|c|}{ Age of Mothers/Caregivers } \\
\hline$<20$ Years & 6 & $7 \%$ \\
\hline 20 to 30 Years & 25 & $31 \%$ \\
\hline 30 To $<40$ Years & 46 & $57 \%$ \\
\hline 40 - 50 Years & 4 & $5 \%$ \\
\hline Total & 81 & $100 \%$ \\
\hline \multicolumn{3}{|c|}{ Education of Mothers/Caregivers } \\
\hline Primary & 6 & $8 \%$ \\
\hline Secondary & 38 & $47 \%$ \\
\hline Tertiary & 35 & $43 \%$ \\
\hline None & 2 & $2 \%$ \\
\hline Total & 81 & $100 \%$ \\
\hline \multicolumn{3}{|c|}{ Occupation of Mothers/Caregivers } \\
\hline Student & 6 & $8 \%$ \\
\hline Artisan & 10 & $12 \%$ \\
\hline Domestic Staff & 5 & $6 \%$ \\
\hline Service Provider & 32 & $40 \%$ \\
\hline Professional & 10 & $12 \%$ \\
\hline Housewife & 18 & $22 \%$ \\
\hline Total & 81 & $100 \%$ \\
\hline
\end{tabular}

Table 2. Onset of Nevirapine prophylactic therapy.

\begin{tabular}{ccc}
\hline Onset of Nevirapine Prophylactic Therapy & Frequency & Percentage \% \\
\hline At Birth & 26 & $32 \%$ \\
$0-1$ Weeks & 16 & $20 \%$ \\
$2-4$ Weeks & 12 & $15 \%$ \\
$>4$ Weeks & 25 & $31 \%$ \\
No Response & 2 & $2 \%$ \\
Total & 81 & $100 \%$ \\
\hline
\end{tabular}




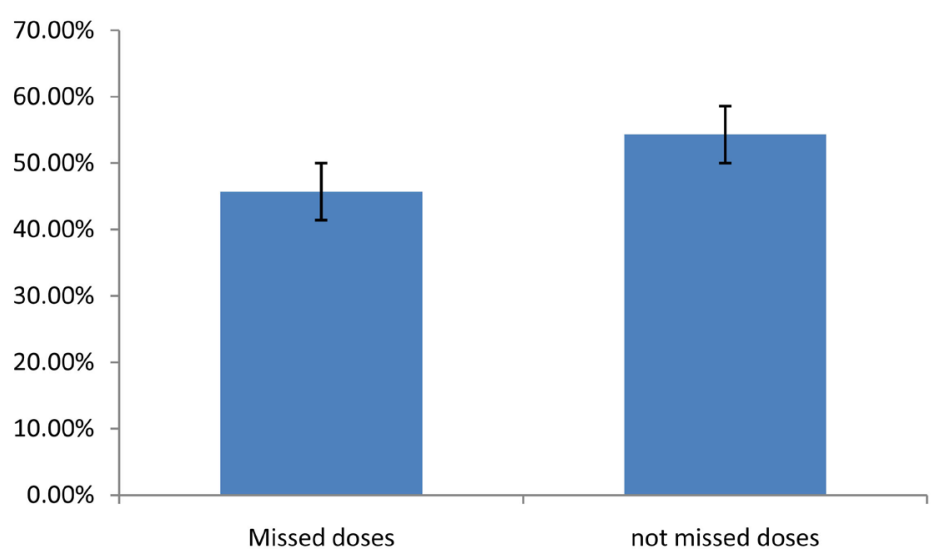

Figure 1. Distribution of respondents on missed doses.

Table 3. Frequency of respondents that missed doses of Nevirapine.

\begin{tabular}{ccc}
\hline Duration of Missed Doses & Number & Percentage \% \\
\hline $24-48$ Hours & $18 \%$ & $49 \%$ \\
3 Days & 9 & $24 \%$ \\
Weeks & 10 & $27 \%$ \\
Total & 37 & $100 \%$ \\
\hline
\end{tabular}

Table 4. Reasons missed nevirapine doses for infants. *

\begin{tabular}{ccc}
\hline Reasons for Missed Doses & Number & Percentage \% \\
\hline Too Busy & 9 & $18 \%$ \\
Away from Home & 13 & $25 \%$ \\
Changes in Daily Routine & 8 & $16 \%$ \\
Not Willing to Give & 1 & $2 \%$ \\
Ran Out of Pills & 12 & $23 \%$ \\
Not Happy Giving Pills & 2 & $4 \%$ \\
I Have Other Drugs I Give & 2 & $4 \%$ \\
Side Effects: & & \\
1. Skin Rash & 3 & $6 \%$ \\
2. Loss of Appetite & 1 & $2 \%$ \\
Total & 51 & $100 \%$ \\
\hline
\end{tabular}

*Respondents gave multiple responses.

Table 5. Frequency and number of respondents that repeated missed doses.

\begin{tabular}{ccc}
\hline Repetition of Missed Doses & Number & Percentage $\%$ \\
\hline Yes & 22 & $60 \%$ \\
No & 15 & $40 \%$ \\
Total & 37 & $100 \%$ \\
\hline If Yes When (n= 22) & & \\
After Getting Home & 7 & $32 \%$ \\
As Soon as Possible & 10 & $46 \%$ \\
When I Remember & 5 & $22 \%$ \\
Total & 22 & $100 \%$ \\
\hline
\end{tabular}


their doses. Sixty percent repeated missed doses and the majority (46\%) repeated the missed doses as soon as possible.

Table 6 describes the reason for missing doses of nevirapine without doctor's consent while Table 7 shows knowledge about implications of missing doses of nevirapine. Only $10 \%$ of the patients stop their medication without the doctors' knowledge and this is mainly due to illness. Fifty-seven percent of the respondents knew the implications of stopping nevirapine without doctors' prescription.

Table 8 shows suggestions of mothers on factors affecting adherence. Only 19 patients responded to this question and $48 \%$ of these patients felt that the cost of pills and $21 \%$ felt the availability of drugs at the local pharmacy amongst other factors affect adherence.

Figure 2 shows the prevalence of adherence rates, $85.2 \%$ took $\geq 95 \%$ of the prescribed medications (good or high adherence), $8.2 \%$ took $80 \%$ - $95 \%$ of doses (moderate adherence) while $6.2 \%$ took $<80 \%$ of prescribed medicines (low Adherence).

Table 9 shows the association between the reasons for missed doses, and adherence levels. The reasons for missed doses were significantly associated with the adherence levels $(\mathrm{p}<0.05)$. Table 10 shows the relationship between the sociodemographic data and adherence levels. Gender, age of child and mother, level of education and occupation of the mothers did not significantly affect the level of adherence ( $\mathrm{p}>0.05)$.

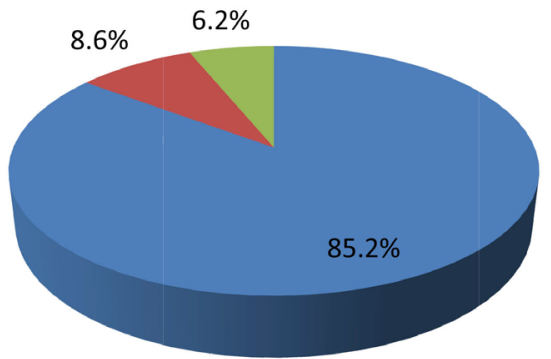

High adherence

Moderate adherence

Low adherence

Figure 2. Prevalence of adherence rate.

Table 6. Stopping of drug without doctors' consent.

\begin{tabular}{ccc}
\hline Stoppage of Drug without Informing the Doctor $(\mathbf{n}=\mathbf{8})$ & Number & Percentage $\%$ \\
\hline Yes & 8 & $10 \%$ \\
No & 69 & $85 \%$ \\
No Response & 4 & $5 \%$ \\
\hline If Yes Why ( $=8)$ & & \\
Sickness & 3 & $38 \%$ \\
No Reason & 2 & $25 \%$ \\
Because of Side Effect & 2 & $25 \%$ \\
Financial Constraint & 1 & $12 \%$ \\
\hline
\end{tabular}


Table 7. Knowledge of respondents on implication of missing doses.

\begin{tabular}{ccc}
\hline Do You Know the Implications of Missing Doses & Number & Percentage \% \\
\hline Yes & 46 & $57 \%$ \\
No & 33 & $41 \%$ \\
No Response & 2 & $2 \%$ \\
Total & $\mathbf{8 1}$ & $100 \%$ \\
\hline
\end{tabular}

Table 8. Suggestions for improving drug administration.

\begin{tabular}{ccc}
\hline Factors That Could Improve Adherence & Number & Percentage \% \\
\hline Cost of Pills & 9 & $48 \%$ \\
Availability of Drugs at Local Pharmacy & 4 & $21 \%$ \\
Route of Administration of Pills & 2 & $10 \%$ \\
Reducing the Frequency of Giving Pills & 3 & $16 \%$ \\
Enhancing the Taste of Pills & 1 & $5 \%$ \\
\hline
\end{tabular}

Table 9. Relationship between adherence rate and reasons for missed doses.

\begin{tabular}{|c|c|c|c|c|c|c|}
\hline \multicolumn{7}{|c|}{ Adherence } \\
\hline & $\begin{array}{c}\text { High } \\
\text { Adherence }\end{array}$ & $\begin{array}{l}\text { Moderate } \\
\text { Adherence }\end{array}$ & $\begin{array}{c}\text { Low } \\
\text { Adherence }\end{array}$ & Total & $X^{2}$ & p-value \\
\hline Reasons for Missing Doses & & & & & 25.94 & $0.03^{*}$ \\
\hline Too Busy & $6(75 \%)$ & $0(0 \%)$ & $2(25 \%)$ & $8(100 \%)$ & & \\
\hline Away from Home & $9(82 \%)$ & $2(18 \%)$ & $0(0 \%)$ & $11(100 \%)$ & & \\
\hline Changes in My Routine & $2(67 \%)$ & $0(0 \%)$ & $1(33 \%)$ & $3(100 \%)$ & & \\
\hline Not Willing to Give & $1(100 \%)$ & $0(0 \%)$ & $0(0 \%)$ & $1(100 \%)$ & & \\
\hline Ran Out of Pills & $6(86 \%)$ & $1(4 \%)$ & $0(0 \%)$ & $7(100 \%)$ & & \\
\hline Not Happy Giving Pills & $0(0 \%)$ & $0(0 \%)$ & $1(100 \%)$ & $1(100 \%)$ & & \\
\hline I Have Other Drugs I Give & $0(0 \%)$ & $2(100 \%)$ & $1(25 \%)$ & $2(100 \%)$ & & \\
\hline I Get Side Effects & $1(25 \%)$ & $2(50 \%)$ & $1(25 \%)$ & $4(100 \%)$ & & \\
\hline Total & $25(68 \%)$ & $7(19 \%)$ & $5(13 \%)$ & $37(100 \%)$ & & \\
\hline
\end{tabular}

${ }^{*} \mathrm{p}<0.05$ is statistically significant.

Table 10. Relationship between adherence rate and sociodemographic data.

\begin{tabular}{ccccccc}
\hline & \multicolumn{3}{c}{ Adherence } & & & \\
\cline { 2 - 3 } Sociodemographic Data & $\begin{array}{c}\text { High } \\
\text { Adherence }\end{array}$ & $\begin{array}{c}\text { Moderate } \\
\text { Adherence Adherence }\end{array}$ & Low & Total & $X^{2}$ & p-value \\
& 29 & 3 & 2 & $34(42 \%)$ & & \\
\hline Gender & 37 & 3 & 7 & $47(58 \%)$ & \\
Male & & & & 0.426 \\
Female & & & &
\end{tabular}




\section{Continued}

\begin{tabular}{|c|c|c|c|c|c|c|}
\hline Total & 66 & 6 & 9 & $81(100 \%)$ & & \\
\hline Age of Child & & & & & 3.24 & 0.517 \\
\hline 0 to 2 Weeks & 3 & 0 & 0 & $3(4 \%)$ & & \\
\hline 2 to $<4$ Weeks & 8 & 0 & 2 & $10(12 \%)$ & & \\
\hline$>4$ Weeks - 6 Weeks & 51 & 10 & 7 & $68(84 \%)$ & & \\
\hline Total & 62 & 10 & 9 & $81(100 \%)$ & & \\
\hline \multicolumn{7}{|l|}{ Age of Mothers } \\
\hline$<20$ Years & 5 & 0 & 1 & $6(7 \%)$ & 2.31 & 0.888 \\
\hline 20 to $<30$ Years & 20 & 3 & 2 & $25(31 \%)$ & & \\
\hline 30 to $<40$ Years & 36 & 6 & 4 & $46(57 \%)$ & & \\
\hline 40 - 50 Years & 4 & 0 & 0 & $4(5 \%)$ & & \\
\hline Total & 65 & 9 & 7 & $81(100 \%)$ & & \\
\hline Level of Education & & & & & 11.8 & 0.065 \\
\hline Primary & 4 & 0 & 2 & $6(8 \%)$ & & \\
\hline Secondary & 30 & 5 & 3 & $38(47 \%)$ & & \\
\hline Tertiary & 28 & 5 & 2 & $35(43 \%)$ & & \\
\hline None & 0 & 1 & 1 & $2(2 \%)$ & & \\
\hline Total & 62 & 11 & 8 & $81(100 \%)$ & & \\
\hline \multicolumn{7}{|l|}{$\begin{array}{c}\text { Occupation of } \\
\text { Mothers/Caregivers }\end{array}$} \\
\hline Student & 6 & 1 & 0 & $7(9 \%)$ & 16.24 & 0.090 \\
\hline Artisan & 6 & 1 & 2 & $9(11 \%)$ & & \\
\hline Domestic Staff & 5 & 0 & 0 & $5(6 \%)$ & & \\
\hline Service Provider & 25 & 5 & 2 & $32(39 \%)$ & & \\
\hline Professional & 10 & 0 & 0 & $10(12 \%)$ & & \\
\hline House Wife & 18 & 0 & 0 & $18(22 \%)$ & & \\
\hline Total & 70 & 7 & 4 & $81(100 \%)$ & & \\
\hline
\end{tabular}

$\mathrm{p}<0.05$ is statistically significant.

\section{Discussions}

Caregivers of eighty-one infants in the age bracket $0-6$ weeks were recruited from three hospitals within the Lagos mainland with a predominance of females with the majority within the reproductive age and actively involved with child rearing activities. Females have been documented to be more affected by HIV than males and are therefore important caregivers. Literature on the probable effects of gender on the course of HIV infection suggests that there is little evidence for gender differences in disease evolution. Although a few clinical studies showed significantly better treatment outcomes in women compared with men, women were more likely to be less adherent to antiretroviral and to have 
non-structured treatment interruptions than men. Studies show female gender presents an added difficulty with access and adherence to antiretroviral therapy. Infants and children rely on caregivers to administer their medication and these caregivers usually mothers may also be infected with HIV and experiencing their own health and treatment challenges that could affect adherence [22] [23] [24] [25] [26].

In this study, adherence to antiretroviral prophylaxis in HIV exposed infants in the first 6 weeks of life was assessed using verbal reports. Verbal reports are often used to assess adherence to medication among adults and children and this measure of adherence has been previously evaluated in treatment studies. Prophylactic adherence in this study showed rates that are comparable to the adherence rates found in other countries [27] [28] [29] [30] [31]. In a study [32], prophylactic adherence determined by maternal verbal reports exceeded $90 \%$ at all clinic visits in the 6 week period.

Previous studies suggest adherence reported by caregivers' over-estimates adherence to ARV treatment compared with other measures in HIV infected children [33] [34]. The finding of patients with low adherence rates among the study population calls for intensification of counseling on adherence and should continue to be an integral part of prevention of mother to child transmission. Adherence levels greater than $95 \%$ are required to maintain virologic suppression [35].

A total of 37 out of 81 mothers admitted to missing dose of nevirapine for their infants either single or multiple doses. Previous studies had evaluated the number of doses that can be missed consecutively in the pediatric population for the concentration to fall below the required level $(100 \mathrm{ng} / \mathrm{ml}-10$ times the in vitro $50 \%$ concentration against HIV-1). It was concluded that infants who miss two to three consecutive doses can still obtain the nevirapine concentration of $100 \mathrm{ng} / \mathrm{ml}$, therefore they would need to receive at least twice weekly doses given a maximum of 72 hours apart [36] [37].

As in a previous study [38], in which factors responsible for missed appointments or dosing regimen was associated with levels of adherence and could predict adherence to antiretroviral treatment, this study documented an association between reasons for missed doses and adherence.

Only $32 \%$ of the infants started nevirapine at birth. In a previous study, only $68 \%$ of infants ingested the medication at birth [30]. In a large-scale cross-sectional study conducted in four African countries, similar gaps are reported [39]. Poor rates of initiation of prophylaxis at birth by infants have been attributed to low rates of institutional delivery because medications are often available only in health facilities [40] [41] [42] [43] [44]. Early initiation of prophylactic nevirapine could also result from awareness of the mother to her HIV status and knowledge about PMTCT. Unfortunately, we did not document place of delivery of the infants in this present study.

Counselling should remphasize the importance of not missing doses irrespective of the reasons. Reasons identified to be significant in this study should be a 
focus of discussions during counseling sessions. Surprisingly there was no significant association between gender, level of education, occupation and age of children and mothers with adherence.

Concerns have been expressed about the possibility of adverse effects associated with exposure to short term antiretroviral prophylaxis for the exposed child. In this study, only $25.0 \%$ of respondents ever stopped giving nevirapine (NVP) because of side effects. NVP is generally well tolerated; its most frequent adverse events are a maculopapular rash and liver transaminase elevation [45] [46]. Although rash in most instances is mild and self-limited, in up to $6 \%$ of patients it is the cause of NVP discontinuation [11], and there are anecdotal reports of Stevens-Johnson syndrome [47]. The incidence of rash complicating the first few weeks of treatment with NVP can be diminished by adding corticosteroids for 2 weeks to the standard recommendation, or by using a slowly escalating dose which is proven to be pharmacokinetically safe [48] [49].

This study had some limitations. The findings should be interpreted with caution as the study was hospital-based and therefore limited to those patients seen at presentation. We did not achieve the desired sample size because of logistics and the fact that a large number of caregivers refused consent. In all cases the interviews were voluntary however, few patients attended on days of survey. and we had a lot of caregiver turnover. Other limitations of our study include potential errors in the recording of information or missing data, which could be attributed to different educational levels of the respondents. Also, variation in the relationship of the caregiver to the child could affect the responses as not all the caregivers were mothers who naturally will have more details of drug therapy.

We did not have data on place of delivery. Other researchers have also reported the place of delivery to be an important and significant predictor of ingesting medication at birth [43] [44].

\section{Conclusion}

The human immunodeficiency virus (HIV) can be transmitted from an HIV-positive woman to her child during pregnancy childbirth and breastfeeding. Infants and children rely on caregivers to administer their medications. The adherence rates found in this study are comparable to other studies in developing countries. But these rates are still low for good clinical outcomes. Different levels of adherence were documented with the majority having good or high adherence. Not all of the infants started treatment at birth and Institutional delivery should be encouraged to improve early initiation of prophylaxis. The finding of patients with low adherence rates among the study population calls for intensification of counselling on adherence and should continue to be an integral part of prevention of mother to child transmission. Counselling should remphasize the importance of not missing doses and the reasons identified to be significant in this study should be the focus of discussions during counseling sessions. Improved access to antiretroviral agents and improved care delivery systems are important. 


\section{Conflicts of Interest}

The authors declare no conflicts of interest regarding the publication of this paper.

\section{References}

[1] UNAIDS (2011) Report on the Global HIV/AIDS Epidemic. UNAIDS, Geneva.

[2] AVERT. Prevention of Mother-to-Child Transmission (PMTCT) of HIV.

[3] Newell, M. (2006) Current Issues in the Prevention of Mother to Child Transmission of HIV-1. Transactions of the Royal Society of Tropical Medicine and Hygiene, 100, 1-5. https://doi.org/10.1016/j.trstmh.2005.05.012

[4] Federal Government of Nigeria (2011) National Guidelines on Prevention of Mother to Child Transmission (PMTCT) of HIV in Nigeria. Federal Ministry of Health, Abuja, Nigeria.

[5] Bedri, A., Gudetta, B., Isehak, A., Kumbi, S., Lulseged, S. and Six Week Extended-Dose Nevirapine (SWEN) Study Team (2006) Extended-Dose Nevirapine to 6 Weeks of Age for Infants to Prevent HIV Transmission via Breastfeeding in Ethiopia, India, and Uganda: An Analysis of Three Randomized Controlled Trials. The Lancet, 372, 300-313. https://doi.org/10.1016/S0140-6736(08)61114-9

[6] Coovadia, H.M., Brown, E.R., Fowler, M.G., Chipato, T., Moodley, D. and Manji, K. (2012) Efficacy and Safety of an Extended Nevirapine Regimen in Infant Children of Breastfeeding Mothers with HIV-1 Infection for Prevention of Postnatal HIV-1 Transmission (HPTN 046): A Randomized, Double-Blind, Placebo-Controlled Trial. The Lancet, 379, 221-228. https://doi.org/10.1016/S0140-6736(11)61653-X

[7] Chasela, C., Hudgens, M., Jamieson, D., Kayira, D., Hosseinipour, M.C., Kourtis, A.P., et al. (2010) Maternal or Infant Antiretroviral Drugs to Reduce HIV-1 Transmission. The New England Journal of Medicine, 362, 2271-2281.

https://doi.org/10.1056/NEJMoa0911486

[8] Cohen, K., Hopkins, J., Ingraham, R., et al. (1991) Characterisation of the Binding Site for Nevirapine, a Non-Nucleoside Inhibitor of HIV Type 1 Reverse Transcriptase. The Journal of Biological Chemistry, 266, 14670-14685.

[9] Montaner, J., Reiss, P., Cooper, D., et al. (1998) A Randomized, Double-Blind Trial Comparing Combinations of Nevirapine, Didanosine, and Zidovudine for HIV-Infected Patients: The INCAS Trial. JAMA, 279, 930-937. https://doi.org/10.1001/jama.279.12.930

[10] D’Aquila, R., Hughes, M., Johnson, V., et al. (1996) Nevirapine, Zidovudine and Didanosine Compared with Zidovudine and Didanosine in Patients with HIV-1 Infection. A Randomized, Double-Blind, Placebo-Controlled Trial. ACTG 241. Annals of Internal Medicine, 124, 1019-1030. https://doi.org/10.7326/0003-4819-124-12-199606150-00001

[11] Richman, D., Havlir, D., Corbeil, J., et al. (1994) Nevirapine Resistance Mutations of Human Immunodeficiency Virus Type 1 Selected during Therapy. Journal of Virology, 68, 1660-1666.

[12] De Jong, M., Vella, S., Carr, A., et al. (1997) High-Dose Nevirapine in Previously Untreated HIV Type-1 Infected Persons Does Not Result in Sustained Suppression of Virus Replication. The Journal of Infectious Diseases, 175, 966-970. https://doi.org/10.1086/514002

[13] Thomas, T.K., Masaba, R. et al. (2011) Triple-Antiretroviral Prophylaxis to Prevent Mother-to-Child Transmission through Breastfeeding-The Kisumu Breastfeeding 
Study. Kenya: A Clinical Trial. PLoS Medicine, 8, e1001015. https://doi.org/10.1371/journal.pmed.1001015

[14] World Health Organisation (2010) PMTCT Strategic Vision, 2010-2015. Preventing Mother-to-Child Transmission of HIV to Reach the UNGASS and Millennium Development Goals. http://www.who.int/hiv/pub/mtct/strategic vision/en

[15] McMahon, J.H., Jordan, M.R., Kelley, K., Bertagnolio, S., Hong, S.Y., Wanke, C.A., et al. (2011) Pharmacy Adherence Measures to Assess Adherence to Antiretroviral Therapy: Review of the Literature and Implication for Treatment Monitoring. HIVIAIDS, 52, 493-506. https://doi.org/10.1093/cid/ciq167

[16] McNabb, J., Ross, J.W., Abriola, K., Turley, C., Nightingale, C.H. and Nicolau, D.P. (2001) Adherence to Highly Active Antiretroviral Therapy Predicts Virologic Outcome at an Inner-City Human Immunodeficiency Virus Clinic. HIVIAIDS, 33, 700-705. https://doi.org/10.1086/322590

[17] Mills, E.J., Nachega, J.B., Buchan, I., Orbinski, J., Attaran, A., Singh, S., et al. (2006) Adherence to Antiretroviral Therapy in Sub-Saharan Africa and North America. JAMA, 296, 679-690. https://doi.org/10.1001/jama.296.6.679

[18] Orrell, C., Bangsberg, D., Badri, M. and Wood, R. (2003) Adherence Is Not a Barrier to Successful Antiretroviral Therapy in South Africa. AIDS, 17, 1369-1375.

https://doi.org/10.1097/00002030-200306130-00011

[19] Palumbo, P., Lindsey, J.C., Hughes, M.D., Cotton, M.F., Bobat, R., Meyers, T., Bwakura-Dangarembiz, M., Chi, B.H., Musoke, P., Kamthunzi, P., Schimana, W., Purdue, L., Eshleman, S.H., Abrams, E.J., Millar, L., Petzold, E., Mofenson, L.M., Jean-Philippe, P. and Violari, A. (2010) Antiretroviral Treatment for Children with Peripartum Nevirapine Exposure. The New England Journal of Medicine, 363, 1510-1520. https://doi.org/10.1056/NEJMoa1000931

[20] NIAID (2004) Paediatric AIDS Clinical Trials Group.

[21] Zegeye, S. and Sendo, H.G. (2015) Adherence to Antiretroviral Therapy among HIV-Infected Children Attending HiwotFana and Dil-Chora ART Clinic at Referral Hospitals in Eastern Ethiopia. Journal of HIV for Clinical and Scientific Research, 2, 8-14. https://doi.org/10.17352/2455-3786.000007

[22] Nicastri, E., Leone, S., Angeletti, C., Palmisano, L., Sarmati, L., Chiesi, A., Geraci, A., Vella, S., Narciso, P., Corpolongo, A. and Andreoni, M. (2007) Sex Issues in HIV-1-Infected Persons during Highly Active Antiretroviral Therapy: A Systematic Review. Journal of Antimicrobial Chemotherapy, 60, 724-732. https://doi.org/10.1093/jac/dkm302

[23] Prins, M., Meyer, L. and Hessol, N.A. (2005) Sex and the Course of HIV Infection in the Pre- and Highly Active Antiretroviral Therapy Eras. AIDS, 19, 357-370. https://doi.org/10.1097/01.aids.0000161765.75663.27

[24] Collazos, J., Asensi, V. and Cartón, J.A. (2007) Sex Differences in the Clinical, Immunological and Virological Parameters of HIV-Infected Patients Treated with HAART. AIDS, 21, 835-843. https://doi.org/10.1097/QAD.0b013e3280b0774a

[25] Berg, K.M., Demas, P.A., Howard, A., Schoenbaum, E.E., Gourevitch, M.N. and Arnsten, J.H. (2004) Gender Differences in Factors Associated with Adherence to Antiretroviral Therapy. Journal of General Internal Medicine, 19, 1111-1117. https://doi.org/10.1111/j.1525-1497.2004.30445.x

[26] Tapp, C., Milloy, M.J., Kerr, T., Zhang, R., Guillemi, S., Hogg, R.S., Montaner, J. and Wood, E. (2011) Female Gender Predicts Lower Access and Adherence to Antiretroviral Therapy in a Setting of Free Healthcare. BMC Infectious Diseases, 11, 86. https://doi.org/10.1186/1471-2334-11-86 
[27] Chesney, M.A. (2000) Factors Affecting Adherence to Antiretroviral Therapy. Clinical Infectious Diseases, 30, S171-S176. https://doi.org/10.1086/313849

[28] Liu, H., Golin, C.E., Miller, L.G., Hays, R.D., Beck, C.K., Sanandaji, S., Christian, J., Maldonado, T., Duran, D., Kaplan, A.H. and Wenger, N.S. (2001) A Comparison of Multiple Measures of Adherence to HIV Protease Inhibitors. Annals of Internal Medicine, 136, 175. https://doi.org/10.7326/0003-4819-134-10-200105150-00011

[29] Nemes, M.I.B., Carvalho, H.B. and Souza, M.F.M. (2004) Antiretroviral Therapy Adherence in Brazil. AIDS, 18, S15-S20. https://doi.org/10.1097/00002030-200406003-00004

[30] Weiser, S. and Hardon, L. (2003) Barriers to Antiretroviral Adherence for Patients Living with HIV Infection and AIDS in Botswana. Journal Acquired Immune Deficiency Syndrome, 34, 281-288. https://doi.org/10.1097/00126334-200311010-00004

[31] Safren, S.A., Kumarasamy, N., James, R., Raminani, S., Solomon, S. and Mayer, K.H. (2005) ART Adherence, Demographic Variables and CD4 Outcome among HIV-Positive Patients on Antiretroviral Therapy in Chennai, India. AIDS Care, 17, 853-862. https://doi.org/10.1080/09540120500038439

[32] Desmond, A., Moodley, D. and Coovadia, H. (2015) Evaluation of Adherence Measures of Antiretroviral Prophylaxis in HIV Exposed Infants in the First 6 Weeks of Life. BMC Pediatrics, 15, 23. https://doi.org/10.1186/s12887-015-0340-9

[33] Müller, A.D., Bode, S., Myer, L., Roux, P. and von Steinbüchel, N. (2008) Electronic Measurement of Adherence to Pediatric Antiretroviral Therapy in South Africa. The Pediatric Infectious Disease Journal, 27, 257-262. https://doi.org/10.1097/INF.0b013e31815b1ad4

[34] Bagenda, A., Barlow-Mosha, L., Bagenda, D., Sakwa, R., Fowler, M.G. and Musoke, P.M. (2011) Adherence to Tablet and Liquid Formulations of Antiretroviral Medication for Pediatric HIV Treatment at an Urban Clinic in Uganda. Annals of Tropical Paediatrics, 31, 235-245. https://doi.org/10.1179/1465328111Y.0000000025

[35] Bartlett, J.A. (2002) Addressing the Challenges of Adherence. JAIDS Journal of Acquired Immune Deficiency Syndromes, 29, 2-10. https://doi.org/10.1097/00126334-200202011-00002

[36] Shetty, A.K., Coovadia, H.M., Mirochnick, M.M., Maldonado, Y., Mofenson, L.M., Eshelman, S.H., et al. (2003) Safety and Trough Concentrations of Nevirapine Prophylaxis Given Daily, Twice Weekly, or Weekly in Breast-Feeding Infants from Birth to 6 Months. Journal of Acquired Immune Deficiency Syndromes, 34, 482-490. https://doi.org/10.1097/00126334-200312150-00006

[37] Müller, A.D., Jaspan, H.B., Myer, L., Hunter, A.L., Harling, G., Bekker, L.G., et al. (2011) Standard Measures Are Inadequate to Monitor Pediatric Adherence in a Resource-Limited Setting. AIDS and Behavior, 15, 422-431.

https://doi.org/10.1007/s10461-010-9825-6

[38] Mirkuzie A.H., Hinderaker, S.G., Sisay, M.M., Moland, K.M. and Mørkve, O. (2011) Current Status of Medication Adherence and Infant Follow Up in the Prevention of Mother to Child HIV Transmission Programme in Addis Ababa: A Cohort Study. Journal of the International AIDS Society, 14, 50. http://www.jiasociety.org/content/14/1/50

[39] Mirkuzie, A.H., Hinderaker, S.G., Sisay, M.M., Moland, K.M. and Mørkve, O. (2011) Current Status of Medication Adherence and Infant Follow up in the Prevention of Mother to Child HIV Transmission Programme in Addis Ababa: A Cohort Study. Journal of the International AIDS Society, 14, 50.

https://doi.org/10.1186/1758-2652-14-50 
[40] Stringer, E., Ekouevi, D.K., Coetzee, D., Tih, P.M., Creek, T.L., Stinson, K., Giganti, M.J., Welty, T.K., Chintu, N., Chi, B.H., Wilfert, C.M., Shaffer, N., Dabis, F. and Stringer, J.S. (2010) Coverage of Nevirapine-Based Services to Prevent Mother-to-Child HIV Transmission in 4 African Countries. The Journal of the American Medical Association, 304, 293-302.

[41] Dabis, F., Bequet, L., Ekouevi, D.K., Viho, I., Rouet, F., Horo, A., Sakarovitch, C., Becquet, R., Fassinou, P., Dequae-Merchadou, L., Welffens-Ekra, C., Rouzioux, C. and Leroy, V. (2005) Field Efficacy of Zidovudine, Lamivudine and Single-Dose Nevirapine to Prevent Peripartum HIV Transmission. AIDS, 19, 309-318.

[42] Volmink, J., Siegfried, N.L., Van der Merwe, L. and Brocklehurst, P. (2007) Antiretrovirals for Reducing the Risk of Mother-to-Child Transmission of HIV Infection. Cochrane Database of Systematic Reviews, No. 7, CD003510. https://doi.org/10.1002/14651858.CD003510.pub2

[43] Kuonza, L., Tshuma, C.D., Shambira, G.N. and Tshimanga, M. (2010) Non-Adherence to the Single Dose Nevirapine Regimen for the Prevention of Mother-to-Child Transmission of HIV in Bindura Town, Zimbabwe: A Cross-Sectional Analytic Study. BMC Public Health, 10, 218. https://doi.org/10.1186/1471-2458-10-218

[44] Ilomuanya, M.O., Okubanjo, O.O., Azubuike, C.P. and Oguntibeju, A. (2017) Evaluation of the Frequency of Use of Herbal Drugs with Concomitant Administration of Highly Active Antiretroviral Therapy and Its Effect on Medication Adherence in Two Health Care Facilities in South Western Nigeria. Journal of AIDS and HIV Research, 9, 8-16.

[45] Barner, A. and Myers, M. (1998) Nevirapine and Rashes. The Lancet, 351, 1133. https://doi.org/10.1016/S0140-6736(05)79417-4

[46] Havlir, D., Cheesman, S., McLaughin, M., et al. (1995) High-Dose of Nevirapine: Safety, Pharmacokinetics, and Antiviral Effect in Patients with HIV Infection. The Journal of Infectious Diseases, 171, 537-545. https://doi.org/10.1093/infdis/171.3.537

[47] Warren, K., Boxwell, D., Kim, N. and Drolet, B. (1998) Nevirapine Associated Stevens Johnson Syndrome. The Lancet, 351, 567. https://doi.org/10.1016/S0140-6736(98)24008-6

[48] Antón, P., Soriano, V., Jiménez-Nácher, I., et al. (1999) Incidence of Rash and Discontinuation of Nevirapine Using Two Different Escalating Initial Doses. AIDS, 13, 524-525. https://doi.org/10.1097/00002030-199903110-00013

[49] Barreiro, P., et al. (2000) Prevention of Nevirapine-Associated Exanthema Using Slow Dose Escalation and/or Corticosteroids. AIDS, 14, 2153-2157. https://doi.org/10.1097/00002030-200009290-00012 